\title{
Erratum zu: Der Hauptwohnsitz - Ein geeigneter Indikator zur Abbildung des räumlichen Lebensmittelpunktes junger Senior/ innen?
}

Diskutiert an den empirischen Befunden zu Personen im Alter von 55 bis 65 Jahren in sechs ausgewählten österreichischen Landgemeinden

\section{Tatjana Fischer ${ }^{1}$}

Online publiziert: 22. März 2016

(C) Springer-Verlag Berlin Heidelberg 2016

\section{Erratum zu:}

STANDORT (2015) 39(4):200-206

DOI 10.1007/s00548-015-0398-5

Im Artikel ist auf Seiten 200 und 201 Meldegesetz, § 1, Z 7 anstelle von Meldegesetz, § 1 Abs. 7 aufgeführt. Desgleichen steht auf den Seiten 200 und 205 Meldegesetz $\S 1, \mathrm{Z} 8$ anstelle von Meldegesetz, § 1 Abs. 8. Diese Fehler werden nun durch dieses Erratum korrigiert.

Die Onlineversion des Originalartikels finden Sie unter dem doi:10.1007/s00548-015-0398-5.

\footnotetext{
Mag. Dr. Tatjana Fischer

tatjana.fischer@boku.ac.at

Institut für Raumplanung und Ländliche Neuordnung (IRUB),

Department für Raum, Landschaft und Infrastruktur (RaLI),

Universität für Bodenkultur Wien (BOKU),

Peter Jordan Straße 82, 1190 Wien, Österreich
} 